\title{
Nos Passos de Magalhães de Gonçalo Cadilhe: viagem, evocação histórica e diálogo intercultural num tempo de globalização
}

\author{
Maria de Fátima Gil \\ Universidade de Coimbra - CITCEM
}

Resumo: Gonçalo Cadilhe era já um nome conhecido na literatura portuguesa de viagens quando em 2007 propôs ao semanário Expresso uma viagem temática, subordinada à figura de Fernão de Magalhães e à primeira circum-navegação. Chamou-lhe "biografia itinerante". De facto, o projecto - que passou das crónicas do jornal para a publicação em livro e para a difusão em série televisiva - procura trazer a vida do grande navegador para a ribalta, mas distingue-se das biografias tradicionais por enfatizar o lugar do biógrafoviajante na contemporaneidade da sua própria viagem. A articulação de presente e passado no encontro de culturas, o jogo narrativo entre a reconstrução da figura de Magalhães e a representação da multifacetada diferença do Outro, o cruzamento do uno e do diverso na globalização actual, e ainda a sensibilidade do olhar do autor-viajante e o estilo dúctil da sua escrita, tudo isto foram razões substantivas para o enorme êxito que o livro conheceu. Tomando em consideração quer as discussões genológicas sobre biografia e sobre literatura de viagens, quer a questão da busca permanente do exótico no planeta global, o meu artigo pretende estudar a fecunda hibridez desta obra, que, na pós-modernidade, cruza tempos e espaços numa peculiar viagem de demanda intercultural.

Palavras-chave: Fernão de Magalhães, Gonçalo Cadilhe, Literatura e História, Crónica de viagem, Biografia, Pós-modernidade

Abstract: Gonçalo Cadilhe was already a well known name in Portuguese travel literature when in 2007 he proposed to the weekly newspaper Expresso a thematic tour, focused on the figure of Ferdinand Magellan and the first circumnavigation of the world. He called it an "itinerant biography". In fact, the project - which 
expanded from the newspaper's chronicles to a book and a television series - aims at bringing the life of the great navigator to the limelight, but differs from traditional biographies by emphasizing the place of the travelling biographer in the contemporaneity of his own journey.

The combining of present and past in the dialogue of cultures, the narrative connexion between the reconstruction of Magellan's figure and the manifold difference of the Other, the nexus of the unique and the diverse in present-day globalization, the sensitiveness of the traveller's gaze and the ductile style of his writing, all these were substantive reasons for the book's huge success. Therefore, taking into account the genological discussions on biography and travel literature as well as the everlasting search for the exotic in the globalized planet, my paper intends to study the fertile hybridity of a work which, in the age of postmodernity, overlaps times and spaces in a peculiar journey of intercultural quest.

Keywords: Ferdinand Magellan, Gonçalo Cadilhe, Literature and History, Travelogue, Biography, Postmodernity

\section{1.}

No ano de 2008, quando Portugal se surpreendia com um computador portátil produzido no país e baptizado com o nome de Magalhães, ${ }^{1}$ chegou aos escaparates das livrarias um volume de Gonçalo Cadilhe intitulado Nos Passos de Magalhães. Uma Biografia Itinerante. Fruto de uma sua viagem, que esteve também na base de um programa televisivo, o livro reunia um conjunto de crónicas dadas à estampa, desde o ano anterior, na revista Única do semanário Expresso.

Não era a primeira vez que Cadilhe seguia esta prática editorial. Até então, já havia coligido, em três volumes, os textos de viagem inicialmente divulgados nas páginas de diversos periódicos. ${ }^{2}$ Os títulos em causa, Planisfério Pessoal (2005), A Lua Pode Esperar (2006) e África Acima (2007), tinham alcançado um êxito assinalável, atingindo pelo menos duas edições logo no ano de lançamento, ${ }^{3}$ e Nos Passos de Magalhães não iria fugir à regra. A confirmar a boa aceitação junto do público, a escrita de Gonçalo Cadilhe acabou por conquistar também ressonância institucional, tendo África Acima e Nos Passos de Magalhães passado a integrar o acervo de obras literárias recomendadas pelo Plano Nacional de Leitura. 4 
O primeiro contacto de Cadilhe com a personagem histórica de Fernão de Magalhães remonta, alegadamente, a 2003. O autor afirma que descobriu o nauta nessa altura, a bordo de um cargueiro, no Pacífico, através de um livro do neozelandês John Chambers (Cadilhe 2008: 133-134).5 Dois anos depois, quando passou na Argentina, na Baía de San Julián, onde Magalhães lançou ferro no Inverno de 1520, Cadilhe terá consciencializado o quão extraordinário tinha sido navegar à volta do mundo dentro do espaço exíguo e caricatamente frágil de uma nau. 6 Tempos mais tarde, terá pegado noutra biografia sobre o navegador - provavelmente a de Tim Joyner, que ele diz ser a sua preferida (Cadilhe 2008: $21)^{7}$ - e, ao folhear o índice remissivo, descobriu que "Magalhães estivera em todo o lado" (idem: 9). A partir desse momento, gizou o seu plano de viagem.

\section{2.}

Alguns dos objectivos que o autor pretendia alcançar haviam norteado os seus livros desde sempre. Ele mesmo os refere no capítulo introdutório da obra, ao encorajar os leitores "a viajar por conta e curiosidade próprias" (idem: 11) e ao animá-los a viver a viagem como experiência de "solidariedade e (...) integração fraternas" (ibidem). A estes dois propósitos juntava-se, agora, um outro, relacionado com a figura histórica. Vejamos o que sobre isso se afirma, ainda na introdução ao volume:

Fundamental neste livro foi, isso sim, recordar aos portugueses (...) a importância de Fernão de Magalhães na História Universal. Recordar o seu contributo para várias disciplinas do saber europeu, a sua responsabilidade na determinação da verdadeira dimensão do mundo, a sua figura pioneira no encontro de culturas e civilizações e, por fim, recordar a tremenda qualidade heróica e épica da sua figura (...). (idem: 11-12)

Com esta finalidade, Cadilhe desenvolveu um aturado trabalho de pesquisa sobre Magalhães e a circum-navegação, tanto no que toca a textos biográficos de escopo tradicional, como no que diz respeito a ensaios e monografias de matriz histórica. De entre as "pistas textuais" (Pfister 2006: 14-15) seguidas, e sem desmerecer dos ensaios académicos, saliento o relato de António Pigafetta - que acompanhou o nauta na sua viagem 
- e ainda a biografia ficcionalizada de Stefan Zweig sobre Magalhães - que se converteu em referência ineludível para a maior parte das obras dedicadas à circum-navegação (Cadilhe 2008: 21, 100,141). Contudo, o aparato de notas e a vasta lista de referências no final do volume não se limitam à figura e ao feito de Magalhães, dando igualmente testemunho de uma grande preocupação contextualizadora. Acresce a isto que o autor procurou ainda ir além da bibliografia disponível, consultando de viva voz diversos especialistas, cujos depoimentos chegou a integrar, por vezes, no próprio texto.

A intenção de homenagear Fernão de Magalhães impôs a Cadilhe algumas alterações relativamente ao que até aí caracterizava as suas viagens e os livros delas resultantes. Na verdade, se o autor se focava habitualmente na deslocação, no percurso de um local para outro, seguindo, sem plano definido, o seu livre-arbítrio e os condicionalismos que a estrada lhe impunha, desta feita obedecia a um roteiro e concentrava-se nos locais que Magalhães havia pisado. Tal diferença determinou o modo de viajar e até o título do livro, como ele mesmo esclarece na "Nota Introdutória":

Ao contrário dos meus projectos anteriores, aqui o que contava não era viajar, mas chegar. Por isso recorri ao transporte aéreo e limitei-me a ficar em lugares, não a percorrer o espaço que os separa. Assim, Na Rota de Magalhães ou Seguindo Magalhães foi posto de lado. Parecia-me "publicidade enganosa". Nos Passos de Magalhães, pelo contrário, parece-me que aponta para a qualidade sólida, terráquea, sedentária, desta viagem: como quem diz, os passos que ele deu em terra firme, os que deixaram pegadas no solo. (idem: 10)

Esta explicação merece alguns breves comentários.

Note-se, antes de mais, que o autor aceitou utilizar o avião - contra todas as suas convicções - porque a logística do empreendimento a isso obrigava. Mas a cedência significou, para ele, uma perda importante. Afinal, ao eliminar do trajecto a medida humana, Cadilhe foi forçado a suprimir um elemento essencial da sua concepção de viagem.

No que diz respeito ao título da obra, as palavras do autor são interessantes não só pela eficácia persuasiva, mas também pela originalidade com que pretendem justificar um padrão já consagrado como subgénero da literatura biográfica. Refiro-me à biografia em 
molde de escrito de viagem (travelogue), i.e., como busca e representação de pistas sobre uma figura histórica através do percurso efectivo do biógrafo na peugada dessa mesma figura. É certo que quase toda a escrita biográfica obriga os autores a deslocações, em busca de informação. Todavia, Manfred Pfister, estudioso alemão das categorias do drama e da literatura de viagens, frisa que as biografias tradicionais tendem a escamotear essas jornadas, enquanto no travelogue os biógrafos transformam a sua própria demanda em objecto de análise e/ou em princípio de organização textual (Pfister 2006: 22). Segundo Pfister, apesar de o primeiro texto deste tipo ter sido publicado em 1934,8 só meio século mais tarde o biógrafo Richard Holmes definiu o novo modelo de biografia como "a kind of pursuit, a tracking of the physical trail of someone's path through the past, a following of footsteps" (apud idem: 25). ${ }^{9}$ O título do volume Nos Passos de Magalhães e, sobretudo, a feliz expressão do subtítulo, Uma Biografia Itinerante, situam a obra nesta moderna tradição.

Por fim, o trecho de Cadilhe acima citado coloca ainda a questão dos lugares que, no seu périplo, serão elegíveis para visita e relato. Naturalmente, o viajante anuncia que se deterá nos locais onde o nauta deixou "pegadas no solo". Mas eles são e não são os lugares de Magalhães.

Abstraindo da circunstância de se desconhecer onde realmente nasceu o navegador - Cadilhe opta por Sabrosa, pelo sentido simbólico da composição escultórica inaugurada no centro da vila -, a primeira parte da vida adulta de Magalhães decorre nos lugares de memória (Pierre Nora) da expansão portuguesa, apesar de, muitas vezes, ele não ter deixado lá marcas de monta. A grande maioria desses locais simbólicos e instituidores de identidade deixou, porém, de ter significado com o fim do império. Por isso, o que o viajante irá encontrar são relíquias do passado, incrustadas numa ordem social diferente, que perderam o seu valor substantivo - como referências arquitectónicas de representação política, religiosa ou militar do poder colonial - e até talvez tenham deixado de ser lugares antropológicos (Marc Augé) - i.e., centros de vivificação simbólica do passado e do presente das sociedades em que estão inseridos. Sem um "princípio de sentido para os que o[s] habitam" (Augé 2012: 48), esses locais desempenham agora o papel de meros traços de 
uma outra lógica social, ou, quando muito, enquanto lugares nobres (idem: 73), o ofício de motores da actividade turística na era da globalização.

O mesmo se passa com a segunda metade da vida de Magalhães, depois que ele se muda para Sevilha e comanda a viagem até às Molucas. Aí, é a expansão espanhola que avança para primeiro plano e a presença do nauta não só está historicamente comprovada, como é objecto de representações icónicas de diversa natureza. Contudo, de novo, os lugares de Magalhães serão porventura menos os do nauta do que os da simbolização identitária e relacional dos povos autóctones, eles também aproveitando as características da economia global no domínio do turismo.

Em suma: a viagem de Cadilhe constituirá, por um lado, um exercício de vontade de memória (Nora 1997: 37) e, por outro lado, um percurso por locais contemporâneos mais ou menos glocalizados (Robertson), i.e., definidos numa interdependência dialéctica entre o local e o global. 0 olhar do viajante irá deparar-se com múltiplas dimensões do real e a escrita desse confronto será, então, igualmente reveladora do posicionamento cultural, político e literário do próprio sujeito-viajante.

Todavia, convém ter presente que os lugares mostrados nestas crónicas nunca são, na verdade, os que existem fora do texto. Da mesma maneira que, no transcorrer de uma viagem, se verifica "uma relação fictícia entre olhar e paisagem", porque o viajante não pode ver todo "o espaço da viagem que percorre ou contempla", nem pode integrar-se plenamente nele (Augé 2012: 75), também na transição do olhar para a narrativa persiste uma distância entre realidade e ficção. Apesar de remeterem para um referente real, os locais apresentados são sobretudo lugares ficcionais, pois é a escrita que os constrói, por efeito da acção soberana de um viajante-autor-narrador. É esta figura compósita, ela própria com um referente extratextual e uma identidade criada intratextualmente, que dá forma a esses lugares. Ainda que não possa afastar-se de modo absoluto daquilo que é empiricamente verificável, esta instância, a um tempo real e ficcional, exerce prerrogativas de autoridade exclusiva, não apenas em termos de selecção, ordenação e perspectivação dos elementos, mas também em termos de configuração estética de todo o conjunto.

Por tudo isto, o volume Nos Passos de Magalhães. Uma Biografia Itinerante institui 
um pacto de leitura muito particular. Na verdade, cruza-se neste livro a vivência do presente com a evocação do passado, combinam-se factos com ficção e entretece-se a História com a Literatura para produzir uma obra que se situa na fronteira entre auto e heteroreferencialidade e se mostra, do ponto de vista genológico, triplamente híbrida: como biografia, como travelogue e como autobiografia.

\section{3.}

Debrucemo-nos agora sobre a configuração narrativa da viagem.

$\mathrm{Na}$ transposição das crónicas do semanário Expresso para o livro, Gonçalo Cadilhe procedeu a pequenos rearranjos textuais, mas a sua mudança mais significativa consistiu na ordenação dos relatos de viagem em capítulos. Esta opção tem o efeito de criar uma maior unidade e coerência nos textos, estruturando, simultaneamente, as várias fases da vida do navegador. Assim, os títulos das três primeiras grandes secções cartografam a terra firme no percurso de Magalhães: "Portugal”, “África Oriental”, “Oriente” - embora este último pareça ter sido escolhido mais por razões de simetria compositiva da obra, pois, na realidade, fala tanto da Índia como do Oceano Índico. As três divisões seguintes catalogam os mares - "Atlântico Norte", "Atlântico Sul", "Pacífico" - e o título da última parte fecha topograficamente o círculo da biografia do nauta: "0 globo todo".

Fazendo lembrar as crónicas medievais e renascentistas, cada um destes segmentos começa com um parágrafo que resume o acontecer dos respectivos subcapítulos. ${ }^{10}$ Todavia, à feição informativa junta-se, por vezes, uma vertente comentadora, como podemos constatar, por exemplo, na introdução do capítulo "Oriente":

Os primeiros europeus a navegar no Índico começaram do zero: nada neste canto do globo era comparável ao que conheciam. A terapia de choque calhou também a Magalhães. Presente na batalha de Diu e nas conquistas de Goa e Malaca, ao longo de sete anos no Oriente, o soldado aprendeu, entre outras coisa, a relativizar a dimensão do mundo. (Cadilhe 2008: 41)

Quer no plano da história de Magalhães, quer no plano da deslocação do autorviajante, as crónicas agora transformadas em subcapítulos comprovam a escrita visual e 
absorvente que os leitores já conheciam dos primeiros trabalhos de Gonçalo Cadilhe. Numa linguagem familiar e até coloquial, cheia de humor e de ironia, mas por vezes a raiar o lirismo, o autor gere a atenção do seu público articulando uma grande variedade de técnicas narrativas. Assim, tanto relata episódios - às vezes anedóticos - de modo muito vivo, como utiliza perguntas retóricas para encetar reflexões e comentários; tanto descreve paisagens e monumentos com grande plasticidade, como utiliza referências históricas concretas e frases feitas do século XXI para explicar factos do passado; tanto cita em discurso directo palavras de cidadãos com que se cruza, como regista as impressões e emoções que tudo nele provoca.

Este lado vincadamente subjectivo revela-se também na organização circular dos textos. Por via de regra, eles iniciam-se com um lance de cariz pessoal nos locais visitados e as acções ou reacções descritas são textualizadas como síncronas da percepção e da enunciação. Tal presentificação serve, depois, para introduzir informações sobre esses espaços, tanto na contemporaneidade, como no passado. Da relação de oposição que normalmente se estabelece entre os dois níveis temporais nasce a oportunidade de carrear dados sobre a presença de Magalhães. A fechar, o final regressa ao tempo presente, ao autor-viajante e às suas vivências ou juízos pessoais.

A crónica "Escalas em Moçambique”, no capítulo “África Oriental”, exemplifica bem este procedimento. Abre com um comentário do viajante sobre si mesmo: "Em quase 20 anos com carta de condução nunca fui multado. Alguma vez teria de ser a primeira" (Cadilhe 2008: 31). Seguidamente expõe a situação de partida: o eu-narrador é multado na Ilha de Moçambique por conduzir uma bicicleta em contramão e nem os seus argumentos sentimentais convencem o agente de trânsito: "Num lugar que me recorda tanto o meu Portugal, não é culpa minha que se circule pela esquerda como os ingleses." (ibidem). Após esta constatação passa-se para o plano histórico: atribui-se aos quatro séculos de colonização o motivo de a Ilha de Moçambique fazer lembrar Portugal e a partir daí resumese a expansão dos portugueses na África Oriental e a passagem de Magalhães por tais regiões. No final, o autor volta ao tempo da sua viagem, para terminar com mais um quadro 
da Ilha, que acentua a situação marginal face aos itinerários globais e, no bosquejo da paisagem, cruza o domínio do concreto com o domínio da poesia:

Nos anos cinquenta do século $\mathrm{XX}$, uma ligação ferroviária e um porto novo transferem todo o movimento de mercadorias para Nacala. (...) E a Ilha de Moçambique, apesar da construção de uma ponte, retira-se na timidez contemplativa dos fantasmas da História.

Atravesso essa ponte na melhor hora da chegada - o fim da tarde. (...) 0 calor abranda, o fantasma da História acorda do letargo, as pessoas saem à rua, a vida regressa. Fantasma será Quíloa, aqui celebra-se o presente. (idem: 34 )

Este plano diegético - o da viagem realizada pelo escritor-viajante - cumpre, no que concerne à temática e ao modo de percepção, os dois princípios enunciados no intróito do volume e já acima referidos.

Um deles prende-se com a noção de viagem "como oportunidade de aproximação da grande família humana" (idem: 11). Sob esta óptica, o livro replica traços de que todas as obras de Cadilhe dão testemunho. A saber: uma curiosidade despida de juízos préconcebidos sobre a diferença; o relato de aventuras e contratempos da viagem, superados com a ajuda dos habitantes locais; a descrição das paisagens, dos monumentos e dos homens, no que revelam de alteridade e de semelhança; e, last but not least, um olhar político, aberto e imparcial, sobre o presente e o passado. A este propósito, veja-se um curto exemplo, no final da crónica "Deixar Sevilha":

(...) não posso deixar de sorrir com complacência à placa afixada na igreja de Santa Maria Triana, na margem direita do Guadalquivir. Diz que a viagem de "Magallanes" e Sebastián del Cano foi mais um exemplo da fibra da raça espanhola. E das outras raças, não foi? Não tinham fibras as dezenas de bascos e gregos e nórdicos, que nem espanhol falavam? (idem: 92)

É claro que, como também se percebe nas entrelinhas do trecho, este olhar não esconde, por vezes, o orgulho de ser português - ou não fosse o autor, no seu processo de rememoração, representante de um grupo específico, nacional. Uma prova ainda mais evidente dessa imodéstia acha-se, por exemplo, na crónica "Retalhos de História". 0 viajante 
reproduz aqui o pensamento que lhe ocorre no final de uma conversa com um uruguaio, que disserta sobre o passado do seu país:

Sorrio da indignação personalizada com que Marcelo fala de todos estes factos. Continua com datas, nomes, lugares e descrições minuciosas de tratados, batalhas, extermínios. Desconfio que o professor alfarrabista sabe muito mais do passado do seu país do que eu sei do meu. Mas o passado registado do seu país concentra-se em pouco mais de um par de séculos; o passado registado do meu estende-se por um par de milénios e inclui a descoberta do seu. A um certo momento da História do meu país tem início a História do seu. (idem: 106-107)

Todavia, noutras ocasiões, a voz autoral procura ser crítica e isenta mesmo quando assume a sua identidade pátria. Cadilhe nunca escamoteia, por exemplo, a violência da expansão portuguesa no Índico ${ }^{11}$ e insurge-se contra construções da memória que aí chamam às pelejas dos portugueses com os povos autóctones, por razões económicas e turísticas, "diálogo" ou "encontro cultural" (idem: 38). Além disso, é capaz de destacar como aspecto verdadeiramente positivo do império português da Índia não a construção de fortes ou igrejas, mas a miscigenação que deu origem aos "vários Souza, Cruz, Dias, Antunes" (idem: 52) que ainda encontra em Goa.

A segunda característica desta viagem no século XXI tem a ver com o outro desígnio formulado no capítulo introdutório: o de persuadir o leitor a realizar a sua própria deslocação, longe dos circuitos turísticos e aberto à aventura e à diversidade. Sempre que pode, o autor-viajante deixa perceber até que ponto rejeita o nivelamento imposto pela globalização e pelo turismo de massas.

Para ilustrar a estranheza que tais características da vida moderna provocam nesta demanda dos lugares de Magalhães, tome-se em consideração a passagem do autor na ilha de Guam - a ilha a que o navegador chamou "dos Ladrões”.

O experiente globetrotter Gonçalo Cadilhe encena-se aqui como ingénuo visitante, que esperava encontrar um paraíso pouco conspurcado e se depara com um panorama aberrante, "uma espécie de luna park do mar" (idem: 139), cheio de cadeias americanas de fast food. A esse não-lugar (Marc Augé), de onde os chamorros, os habitantes originais, 
desapareceram há muito, chegam regularmente excursões de japoneses, cujo reconhecimento da ilha o viajante descreve assim:

As excursões de japoneses seguem todas, obedientes, o mesmo programa: sexta de manhã, passeio no banana boat; sábado à tarde, fotografa-se as cascatas de Tafolulu; domingo, almoça-se na Caverna do Pirata e, à noite, vê-se o show da dança do fogo - que é tradicional da Melanésia, não daqui, que estamos na Micronésia, mas isso não tem importância nenhuma para um japonês. E na terça de manhã, visita-se uma espécie de pilar de cimento que é o monumento a Magalhães (...). (idem: 140)

No âmbito da perda de genuinidade por força da moderna indústria do turismo e ainda no contexto de narcisismo e de anonimato que, segundo Marc Augé, caracteriza os não-lugares (Augé 1992: 133-134), a narrativa da voz autoral parodia a banalidade iterativa e inautêntica do circuito turístico contemporâneo. Uma evidente dicotomia turista/viajante - que atravessa este e todos os outros textos de Cadilhe - exprime-se, no passo transcrito, pelo remoque sobre a diferença entre a Melanésia e a Micronésia. 0 viajante, culto, detecta a falsificação, ao passo que os turistas, ignaros, aceitam o embuste sem suspeitas, porque o que procuram na viagem é apenas a diversão exoticizante que os folhetos das agências turísticas lhes prometem. Opondo esse objectivo massificado ao intuito diferenciador da sua própria viagem, o eu-narrador questiona-se divertido sobre o efeito que teria se se desse a conhecer:

(...) quantas mais fotografias iriam eles querer tirar, se soubessem que o turista ao lado do monumento a Magalhães é dele conterrâneo e que está aqui porque anda a seguir-lhe os passos pelo mundo e a escrever sobre ele? (Cadilhe 2008: 140)

A crónica termina em tom reprovador, pois o autor não esconde o seu assombro perante o regime alimentar dos “modernos ilhéus de Guam" (idem: 143). Desta feita, e diferentemente dos europeus do século XVI que aportavam a terras estranhas, a alteridade sobre a qual ele se admira não diz respeito aos mantimentos autóctones, mas precisamente ao fenómeno globalizado e quotidiano da fast food.

Este momento do percurso de Cadilhe, pelo seu carácter grotesco, é talvez o que 
mais incisivamente desmistifica o turismo de massas. Todavia, há outras estações do trajecto do viajante que demonstram como a inevitável inscrição dos lugares de Magalhães no espaço e no tempo acabou por transformá-los em simples cenários de históriaespectáculo. Aduza-se apenas mais um exemplo, desta feita na paragem em Mombaça. Segundo a voz autoral, a cidade tem tudo para se assumir como centro de um itinerário turístico glocalizado: praias, reserva florestal, lojas de souvenirs, a "agitação urbana sempre tão exótica e apelativa para uma pitada de choque cultural" (idem: 35) e ainda a presença portuguesa, assinalada com o Forte Jesus. Contudo, o eu-narrador sublinha até que ponto essa fortaleza deixou de ser, para os habitantes da cidade, um lugar antropológico - não obstante, por todo o lado, se venderem reproduções do monumento. Quando Cadilhe, no final dessa crónica, se dá a conhecer como português aos vendedores de Mombaça, não é primeiramente com o Forte Jesus que eles o relacionam, mas com o futebol luso:

Ah, sim senhor, Portugal, grandes jogadores de futebol. Agora sim, metem conversa, aqui está uma nação que merece "diálogo de culturas", Figo, Oporto, "Christian Ronaldinho", Eusébio, "Maurino". Sim, sim, very good. E já agora, não quer comprar uma escultura em madeira? E sarong de linho? E uma réplica em madeira do Forte Jesus? Nada do Forte Jesus? Nem uma gravura, um postal? (idem: 38-39)

O Forte Jesus de Mombaça só comprova o "fosso entre a funcionalidade quotidiana e o mito perdido" que Marc Augé refere num outro contexto (Augé 2012: 83). Aqui, o espaço arquitectónico serve os objectivos económicos dia após dia, mas esvaziou-se de significado e a sua ligação a Portugal, na prática, tornou-se culturalmente invisível.

A contrastar com esta experiência de perda por via do esvaziamento da História, temos, na obra de Cadilhe, a vivência pessoal de que "les lieux de mémoire ne sont pas ce dont on se souvient, mais là où la mémoire travaille" (Nora 1997: 17-18). Isso, como o livro demonstra, pode verificar-se em qualquer lugar. Pode suceder até no artificialismo de Mombaça, mas ocorrerá certamente com mais facilidade longe dos circuitos massificados, quando o viajante se confrontar, sem ruído, com os restos simbólicos do passado. Um dos pontos altos do livro de Cadilhe, no que toca à afirmação de autonomia de quem viaja e ao 
impulso de evocação histórica que nasce dos lugares de memória, acontece precisamente na visita do eu-narrador ao local onde os navegadores, no arquipélago filipino, celebraram a primeira missa. Aí, na ilha de Limasawa - que "[t]oda a gente nas Filipinas conhece (...), mas quase ninguém sabe onde fica ou como se pode chegar lá" (idem: 146) -, depois de uma travessia numa piroga primitiva, muito semelhante às do tempo de Magalhães, o viajante observa “[a] mão-cheia de choupanas" chamada "barangay Magallanes" (idem: 151) e leva a rememoração histórica ao ponto extremo da identificação: sente o que o nauta poderá ter sentido ao desembarcar na ilhota - que tinha chegado ao paraíso.

\section{4.}

Numa época em que o turismo de massas, a compressão das coordenadas de espaço e tempo e a rapidez informativa da Internet levam alguns estudiosos a anunciar a morte próxima da viagem e da literatura de viagens, ${ }^{12}$ Nos Passos de Magalhães sugere variadas razões para a descoberta individual que toda a aventura viática (ainda) pode significar.

$\mathrm{O}$ autor concretiza, no século XXI, uma odisseia moderna e pessoal por lugares mais ou menos exóticos dispersos por todo o globo. Contudo, as crónicas de viagem de Gonçalo Cadilhe, materializadas na sua escrita viva e dúctil, não apresentam apenas este plano de travelogue autobiográfico. Num contexto temporal de renovado interesse pela História, elas surgem em função da figura de Magalhães e prestam homenagem ao navegador, expondo a óbvia admiração que o biógrafo-viajante nutre pela personagem histórica.

O crítico Manfred Pfister frisa que este modelo de biografia põe em causa a visão autoritativa da escrita biográfica tradicional, mas nem por isso abandona a pretensão de mostrar, com verdade, a vida e a obra do biografado (Pfister 2006: 24). No caso em apreço, a representação do nauta procura recuperar para a memória cultural dos portugueses a figura e o feito de Magalhães e ser tão fiel quanto possível ao seu percurso, assinalando, nos locais por onde ele passou, a sua coragem e ousadia, os muitos obstáculos e vicissitudes da sua empresa e a importância de que esta se revestiu para o conhecimento do mundo.

No que toca à questionação da forma biográfica convencional mencionada por Pfister, ela resulta da interferência do presente na exposição da vida do navegador. Note-se, 
todavia, que essa presença da contemporaneidade ultrapassa aqui as funções de objecto de análise ou princípio de organização textual que o crítico considera características deste tipo de textos (supra). 0 tempo presente tem ainda o papel pós-moderno de descentrar a História e, beneficiando de conhecimentos posteriores aos da época do navegador, criar constelações de sentido que ultrapassam a mera explicação de causa-efeito na existência do nauta. Por seu turno, o passado imiscui-se também no presente, promovendo comparações que, por exemplo, contrastam a antiga glória das Descobertas com a actual decadência dos vestígios do império, contrapõem a afoiteza dos portugueses de antanho à falta de ousadia dos seus descendentes, ou apontam as diferenças entre o contacto inicial com o Outro e algumas construções contemporâneas e massificadas da alteridade.

Por via desta relação dialéctica e desta desconstrução mútua entre passado e presente, o livro de Gonçalo Cadilhe, para além de configurar uma biografia como travelogue, parece-me aproximar-se também do método postal, que a estudiosa alemã Sigrid Weigel (2002) defende como processo capaz de fazer evoluir a Biografia. Esse método, segundo Weigel, não procura apresentar o biografado à luz de conceitos de unidade, continuidade e evolução, mas em sentido literal, como se ele enviasse cartas ou bilhetespostais da sua época e das várias constelações históricas, sociais, económicas, etc. de que a cada momento faz parte. Desta forma, o sujeito biográfico autonomiza-se da evolução causal e uniformizadora que caracteriza as biografias tradicionais e revela-se na sua complexidade, na sua disjunção, até na incoerência dos seus actos paradoxais.

A meu ver, estas crónicas de viagem constituem-se como uma série de verdadeiros postais ilustrados tanto da vida de Fernão de Magalhães, como da vida de Gonçalo Cadilhe. Este escreve-os - e, na verdade, envia-os para o Expresso - dos lugares por onde passou Magalhães, evocando a intrincada figura do nauta e a sua excepcional importância, ao mesmo tempo que expõe, com humor e sensibilidade, o diálogo intercultural, ora mais padronizado, ora mais personalizado, que é possível estabelecer na pós-modernidade, numa viagem à volta do planeta global. 


\section{Bibliografia}

Augé, Marc (2012), Não-Lugares. Introdução a uma Antropologia da Sobremodernidade, trad. Miguel Serras Pereira, Lisboa, Letra Livre.

Cadilhe, Gonçalo (2006), A Lua Pode Esperar, Cruz Quebrada, Oficina do Livro.

-- (2008), Nos Passos de Magalhães. Uma Biografia Itinerante, Cruz Quebrada, Oficina do Livro.

Gil, Maria de Fátima (2008), Uma Biografia "Moderna" dos Anos 30. Magellan. Der Mann und seine Tat de Stefan Zweig, Coimbra, MinervaCoimbra e Centro Interuniversitário de Estudos Germanísticos.

Madelénat, Daniel (1984), La Biographie, Paris, Presses Universitaires de France.

Matos, Mário (2006): “Figurações da Viagem e do Viajante: do 'Maldito Turista' ao 'Cosmopolita Doméstico'” in Ana Gabriela Macedo / Maria Eduarda Keating (org.), Colóquio de Outono. Novos Cosmopolitismos. Identidades Híbridas, Braga, Centro de Estudos Humanísticos da Universidade do Minho, 131-147.

Nora, Pierre (1997), "Entre Mémoire et Histoire. La problématique des lieux", in P.N. (dir.), Les Lieux de Mémoire. I: La République, Paris, Gallimard, 23-43.

Pfister, Manfred (2006), “Autopsie und intertextuelle Spurensuche: Der Reisebericht und seine Vor-Schriften" in Gisela Ecker / Susanne Röhl (Hg.), In Spuren Reisen. Vor-Bilder und Vor-Schriften in der Reiseliteratur, Berlin, Lit, 11-30.

Robertson, Roland (1995), “Glocalization: Time-Space and Homogeneity-Heterogeneity”, in Mike Featherstone / Scott Lash / Roland Robertson (eds.), Global Modernities, London, Sage Publications, 25-44.

Weigel, Sigrid (2002), "Korrespondenzen und Konstellationen. Zum postalischen Prinzip biographischer Darstellungen”, in Christian Klein (Hg.), Grundlagen der Biographik. Theorie und Praxis des biographischen Schreibens, Stuttgart/Weimar, Metzler, 41-54. 
Maria de Fátima Gil é Professora Auxiliar da Faculdade de Letras da Universidade de Coimbra e Investigadora do Centro de Investigação Transdisciplinar Cultura, Espaço e Memória. Doutorou-se em 2005 na Área de Línguas e Literaturas Modernas, Especialidade de Literatura Alemã, com uma dissertação intitulada "Magellan. Der Mann und seine Tat" de Stefan Zweig: um exemplo de biografia "moderna" dos anos 30 sobre uma figura histórica portuguesa (trabalho dado à estampa no ano de 2008). Do seu currículo constam várias publicações no país e no estrangeiro, que versam sobretudo questões de hermenêutica intercultural no contexto luso-alemão e europeu, bem como aspectos da relação dialógica da Literatura com a História. Entre os diversos cargos que tem vindo a desempenhar na Faculdade de Letras da Universidade de Coimbra, Maria de Fátima Gil foi membro da Comissão Coordenadora do Conselho Científico (2006-2009) e Subdirectora da Faculdade (2009-2011). Presentemente é Subdirectora do Departamento de Línguas, Literaturas e Culturas.

\section{NOTAS}

\footnotetext{
${ }^{1}$ Destinado a alunos do 1. ํㅜㄹ ciclo e apresentado oficialmente no Pavilhão Atlântico, em Lisboa, como o primeiro computador português, o Magalhães depressa se revelaria um clone do Classmate PC da Intel, um projecto de baixo custo pensado para os países em vias de desenvolvimento.

2 Nascido na Figueira da Foz, em 1968, e licenciado em Gestão de Empresas, Cadilhe publicou a sua primeira crónica de viagem na revista Grande Reportagem, em 1992, quando o mercado português começava a despertar para este tipo de textos. De então para cá, colaborou em diversas revistas e nos jornais Independente e Expresso. A editora Oficina do Livro tem trazido regularmente para o mercado os volumes que compilam as crónicas das suas viagens.
}

${ }^{3}$ África Acima fora o mais bem sucedido, com sete edições. 
4 O livro África Acima está aconselhado para o 3. ciclo, na secção "Leitura Autónoma", e Nos Passos de Magalhães integra as "Sugestões de Leitura" para o Ensino Secundário. Nesta mesma lista encontra-se ainda o volume $1 \mathrm{Km}$ de cada vez, já posterior (2009). Cf. http://www.planonacionaldeleitura.gov.pt/ escolas/uploads/livros/57_todas_as_listas_2015\%2810\%29.pdf

50 livro de Chambers, New Zealand and the South Pacific Islands (2003), faz parte da conhecida colecção $A$ Traveller's History, da editora inglesa Interlink Publishing Group Inc.

${ }^{6}$ E deixou tal comentário no volume A Lua pode Esperar; cf. Cadilhe 2006: 35.

7 Trata-se da obra Magellan, dada à estampa pelo conhecido biólogo marinho em 1992 e editada pela International Marine Publishing.

8 Pfister refere-se à biografia Quest for Covo (1934), de Alphonse James Albert Symons.

${ }^{9} 0$ crítico cita Richard Holmes a partir da obra Footsteps: Adventures of a Romantic Biographer, publicada em 1985.

10 Esta técnica já tinha sido aplicada nos textos publicados no jornal, embora com informações mais circunscritas.

${ }^{11}$ Leia-se, a título de exemplo, o seguinte passo da crónica "O Gosto do Sangue": "Foi aqui [em Mombaça] que a presença portuguesa inaugurou a ferocidade e a ganância cega que a distinguiria no confronto com as civilizações orientais - essa qualidade moral que hoje Bush utilizaria para designar Bin Laden, e Bin Laden para designar Bush: evil, a maldade." (idem: 37 ).

120 tema não é novo, mas agudizou-se pelo efeito das virtualidades telemáticas da nossa era. Sobre este assunto, veja-se o historial e a posição discordante apresentados pelo crítico Mário Matos (2006). 